\title{
Diversity and seasonal changes in carabid assemblages of a mature, secondary and plantation forest mosaic in the Zhangguangcai Mountains, North-eastern China
}

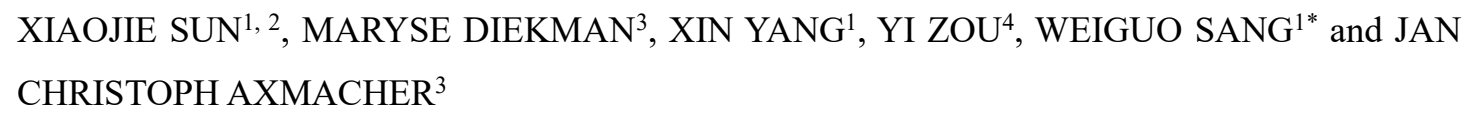

Abstract: 1. While China is promoting the re-establishment of forests across the country on a globally unprecedented scale, the biodiversity harbored by the resulting secondary and plantation forests remains poorly understood. Here, we assess the carabid diversity at Zhangguangcai Mountains in north-eastern China that comprise a unique mosaic of mature forest remnants, secondary forests and forest plantations.

2. We located pitfall traps in five distinct forest types: mature conifer and mature mixed forest, secondary mixed forest, secondary broadleaved forest dominated by birch (Betula platyphylla) and poplar (Populus davidiana), and in larch plantations. We recorded 9,073 carabid beetles representing 42 species, with richness, abundance and diversity of ground beetles all peaking in secondary broadleaved forests. Assemblages sampled in larch plantations were least species rich, but species extrapolation curves indicate a potentially high overall species richness.

3. Carabid communities were clearly differentiated according to forest type, with larch plantations and secondary broadleaved forests containing beetle assemblages distinct from the other three forest types, while the mixed secondary and mature forest types harbored similar assemblages.

4. Carabid communities also showed a clear seasonality in all forest types, with the plantation forest communities remaining distinctly different from the clustered communities of the mature and mixed secondary forest types throughout the year. Broadleaved secondary forest assemblages occupy an intermediate position throughout the sampling season. 
Keywords: ground beetles, forest type, species turnover, community structure, growing season

*Correspondence: Weiguo Sang, College of Life and Environment Sciences, Minzu University of China, Beijing 100081, China. E-mail: swg@muc.edu.cn

\section{Introduction}

Mature forests across the globe have suffered significant declines in the second half of the $20^{\text {th }}$ century, chiefly linked to increasing demands for timber and cultivated land (FAO, 2001). Furthermore, 'natural' forests account for only about a third of the total forest area (Morales-Hidalgo et al., 2015). Of these, $74 \%$ are classified as 'other, naturally regenerated forests', while only $26 \%$ are regarded as 'primary' or mature forests (FAO, 2015b). Particularly between 2010 and 2015, losses of 'natural' forests $\left(\sim 7.6 \mathrm{M}\right.$ ha $\left.\mathrm{y}^{-1}\right)$ were partially offset by a combination of natural forest

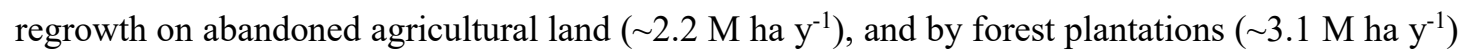
(FAO, 2015b; FAO, 2016). This highlights the increasingly important contribution of naturally regenerating secondary forests and plantation forests towards global forest cover. Nonetheless, $80 \%$ of terrestrial biodiversity are believed to be linked to mature forests, and the ongoing destruction of these forests is seen as a key factor for the rapid biodiversity losses across the world and for the threat of extinction faced by many plant and vertebrate species (Meng, 2006; Watson et al., 2018). Threats to the global species pool associated with the loss of mature forest ecosystems are therefore of significant global concern (Potapov et al., 2008).

China's government has launched globally unprecedented national forest rehabilitation and afforestation programmes (FAO, 2016), chiefly aimed at reducing soil erosion and associated sand and dust storms, as well as enhancing $\mathrm{C}$ sequestration and general improvement of environmental conditions. The scale of these programmes are reflected by the fact that in 2015 , China had naturally regenerated secondary forest and forest plantation areas covering 1,180 $\mathrm{M}$ ha and $790 \mathrm{M}$ ha, respectively. This represents $56.5 \%$ and $37.9 \%$ of China's total forest area, respectively (FAO, 2015a). In addition to initiatives focusing on forest restoration, China's mature forests remnants are now formally fully protected from logging, while significant parts of the plantation and naturally re-growing secondary forests also benefit from strict commercial logging bans (Wang et al., 2007). 
Although naturally regenerated secondary forest and plantation areas are increasing rapidly in coverage, and hence in their relative contribution towards China's forest estate, their potential role in the conservation of biodiversity remains contentious. In contrast to mature forests, China's plantation forests are commonly characterized by an evenly aged, homogenous stand formed by a single species of conifer or by poplar clones (Chen et al., 2014). The herbaceous plant communities in their undergrowth and their nutrient and energy cycling also show distinct differences to mature and secondary forests. Some studies focusing on implications of China's forest plantations for biodiversity conservation have already indicated that these forests can make only limited contributions towards the protection of China's rich biodiversity (Hua et al., 2016; Yu et al., 2002; 2006). At the same time, some plantation forests with low canopy closure appear to allow for a relatively high species richness and density in understory plants (Lemenih et al., 2004; Zou et al., 2015). Furthermore, a comparison of secondary and plantation forest plots located across a wide range of sites in Northeastern China has revealed a surprisingly high diversity in woody plants and ground beetles in secondary and plantation forests (Zou et al., 2019a), while comparisons of ground beetle diversity and assemblage structure between areas dominated by plantation, secondary and mature forest (Zou et al., 2015) showed distinct trait differences, with secondary and particularly plantation forests containing a high abundance and species richness of herbivorous carabids when compared with mature forests. Nonetheless, these studies were conducted across sites that were distributed across large geographic areas and accordingly differed also in their climatic conditions and their history of arthropogenic interferences, while direct comparisons between plots of mature, secondary and plantation forests from the same study region are currently lacking.

Furthermore, secondary forests commonly show distinct temporal shifts in their tree species composition from early pioneer species like birch and poplar to a more diverse mixture of conifer and broadleaved species. Nonetheless, the implications of these changes for their biodiversity, and the resulting relative importance of mature, secondary and plantation forests for the conservation of the local species richness remains poorly researched.

We are addressing persisting knowledge gaps, based on a forested landscape that forms part of the south-eastern slopes of the Zhangguangcai Mountains in Heilongjiang Province on the boundary 
to Jilin Province, Northeast China. In the past, large parts of the mature forests occupying this area were logged, and larch plantations were subsequently established, while secondary forest growth was also observed. Parts of the area are nonetheless still covered in mature forest remnants, harboring trees aged up to at least 400 years, while the secondary and plantation forests were established about 50 years ago. Logging is now banned, and the entire forested environment is protected. The current patchwork of plantation, secondary and mature forests provides an ideal setting to conduct research into the diversity patterns encountered within and between these forest types. In our investigations of forest diversity, we are focusing on one of the most species-rich insect taxa inhabiting these forests (Zou et al., 2015), ground beetles (Coleoptera: Carabidae). With almost 40,000 described species (Carabidae of the World, 2018), ground beetles are highly sensitive to environmental change and show strong habitat specificity (Brandmayr et al., 2005; Lövei \& Sunderland, 1996). They are commonly used in studies of environmental change effects in the context for example of forest management and of differences between forest habitats in the temperate zone of the northern hemisphere (Gao \& Fu, 2009). They are a popular study taxon not least because they are susceptible to sampling using pitfall traps that generate a standardized measure of the activity density of these beetles, and they are more easily identifiable than most other mega-diverse insect taxa (Gnetti et al., 2015; Kotze et al., 2011).

Patterns in insect activity, diversity and community composition change with changes in seasonality. Variations in these patterns are linked to differences in the habitat conditions encountered by the respective insect communities. For example, the conditions and diversity of host trees in different forest types have an immediate impact on the caterpillar abundance and the potential occurrence of spring abundance peaks (Shutt et al., 2019). In addition to direct climaterelated signals, phenological patterns in the vegetation including the development and seasoning of foliage and reproductive organs trigger distinct seasonal changes in the insect community structure (Cardoso et al., 2007). Variations in these factors between distinctly different habitats might also trigger distinct differences in seasonality patterns observed in insect assemblages. For ground beetles that are predominantly predatory or omnivorous and hence often assumed to be less strongly determined directly by the vegetation and its seasonal changes than strictly herbivorous taxa, 
seasonal patterns of species diversity have received limited attention (but see Gnetti et al., 2015; Dornelas et al., 2013).

Here, we compared the abundance, species richness and assemblage composition of ground beetles in the mosaic of mature forest, secondary forest and forest plantations at Zhangguancai Mountains in 4 week-intervals between early June and late August 2016 to establish the variations in species diversity and assemblage composition in the different forest types from early summer to mid-autumn. In our paper, we will test the hypotheses that 1) in line with the proposed importance of mature forests for biodiversity conservation, carabids diversity peaks in mature forest, followed by secondary forests, with the plantations harboring species-poor, homogenous assemblages; that 2) the carabid assemblage structure in larch plantations differs significantly from that in other forest types; and that 3) there are distinct seasonal variations in beetle assemblages that consistently differentiate the assemblages in mature, secondary and plantation forest types.

\section{Material and methods}

\section{Study Site}

The study was carried out in the temperate forests of Hailin City, Heilongjiang Province, in

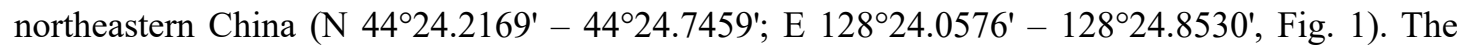
study plots were located in a mountainous region with peaks exceeding $1650 \mathrm{~m}$ that experiences a temperate continental monsoon climate. The average annual temperature is $2.6^{\circ} \mathrm{C}$, with daytime temperatures commonly exceeding $20^{\circ} \mathrm{C}$ in July and August. The average annual precipitation is $551 \mathrm{~mm}$, with most precipitation experienced in the summer months. In the study area, mature and naturally regenerated secondary forests comprised of a mixture of coniferous and broad-leaved trees cover about $92 \%$ of the total forest area, with the rest being formed by plantation forests.

We selected a total of 20 plots across a small altitudinal range between 749 and $985 \mathrm{~m}$ representing five distinct different forest types; larch plantation, secondary broadleaved forest dominated by Populus davidiana and Betula platyphylla, mature mixed forests dominated by Pinus koraiensis, Abies fabri, Picea asperata, B. platyphylla, Tilia tuan, Ulmus pumila and Fraxinus 
mandschurica, mature conifer forests dominated by $P$. koraiensis, accompanied by A. fabri and $P$. asperata, and secondary mixed forests dominated by a wide variety of broadleaved and conifer species, including P. koraiensis, B. platyphylla, T. tuan, U. pumila, F. mandschurica, Acer pictum and Syringa reticulata. Four replicate plots measuring $20 \mathrm{~m} \times 20 \mathrm{~m}$ were established within each forest type to sample ground beetles. The distance between neighbouring plots was at least $50 \mathrm{~m}$, which can be considered independent as the ground beetles generally have small home range (Loreau \& Nolf, 1993; Digweed et al., 1995), with all plots, located within homogenous patches of the respective forest type to limit edge effects (Fig. 1).

\section{Ground beetle sampling}

A $10 \mathrm{~m} \times 10 \mathrm{~m}$ beetle sampling plot was established, with a pitfall trap placed in each corner of this sampling plot, leading to a total of 80 traps used in this study. Each pitfall trap was comprised of a simple plastic cup of about $250 \mathrm{ml}$ volume and a diameter of $7.5-8.0 \mathrm{~cm}$, filled with saturated salt $(\mathrm{NaCl})$ water mixed with several drops of detergent to break the water surface tension. Salt solution is considered odourless and not attracting specimens, thereby generating widely unbiased samples (Kotze et al., 2011). An aluminum roof was fixed about $6 \mathrm{~cm}$ above the trap to prevent rain dilution and limit water evaporation. The traps were positioned with the top rim level with soil surface. Carabids were sampled between late May and the end of August in 2016, cups being emptied after 14 days. We collected the pitfall traps at four distinct times at monthly intervals around June $7^{\text {th }}$, July $4^{\text {th }}$, August $2^{\text {nd }}$ and August $30^{\text {th }}$, respectively, to analyze seasonal changes, with an additional sample taken on June $21^{\text {st }}$. All traps were set and emptied within two days of each other in order to keep sampling synchronicity.

\section{Data Analysis}

For subsequent analysis, data from all pitfall traps on each plot were pooled. For the seasonality analysis, data from all 16 traps representing a forest type were pooled to account for the small monthly sample sizes generated per trap (Devries et al., 1999; Jos et al., 2007), with samples differentiated by the four distinct sampling events. We then used the packages "vegan" (Oksanen et al., 2019) in R (v3.6.1, R Core Team, 2019) to calculate the Chao 1 species richness estimator (Chao, 
1984) as basis for diversity comparisons between different forest types.

We additionally used coverage-based rarefaction and extrapolation (R/E) sampling curves to compare species richness patterns across the samples with varying sample sizes using the R package "iNEXT" (Hsieh et al., 2016), this method allows for standardized unbiased comparisons of the relative species richness between communities (Chao \& Lou, 2012). We used this package to plot the resulting rarefaction and extrapolation sampling curves for the three most widely used members of the Hill number family (species richness, $q=0$; Shannon's entropy index, $q=1$; Simpson diversity, $q=2$ ) (Chao et al., 2014). Extrapolations were standardized to 4000 individuals, representing about four times the smallest sample size we recorded from an individual forest types.

For the analysis of species turnover patterns over the sampling season across the 20 plots, we calculated chord-normalized expected species shared (CNESS) dissimilarity matrices (Trueblood et al., 1994), based on an open source R script (Zou \& Axmacher, 2019b) to analysis data and create the ordination plots. CNESS dissimilarity matrices can be calculated for different sample sizes via changes of the sample size parameter $m$, with low values (extreme: $m=1$ ) emphasizing the similarity in dominant species, and large values of $m$ providing an overview of overall changes in the assemblages. In this study, we calculated the matrices for $m=1$ and for $m=10$ as the largest common sample size of all samples.

Hierarchical Partitioning for Redundancy Analysis and Canonical Correspondence Analysis were then used to analyze changes in the carabid assemblage composition in relation specifically to habitat type and seasonality using the R package "devtools" (Wickham et al., 2019) and "rdacca.hp" (Lai, 2019). In this context, the "rdacca.hp" package specifically allows calculations of the respective proportion of every explanatory variable to the explained variance, based on the Hierarchical Partitioning theory. Entities in the rdacca plot represent carabid species as response variable, as well as study plots representing the different habitat types and sampling events as explanatory variables. Due to the large number of ' 0 ' values in the data-set, the carabids data matrix was Hellinger-transformed (Legendre \& Gallagher, 2001).

\section{Results}




\section{Species compositions}

We caught 9073 ground beetle specimens representing 42 species in 18 genera. We were able to verify scientific species identities for 37 of the 42 species, with the remaining five morphospecies all securely identified to genus level. The total recorded species richness was highest in the secondary broadleaved forests $(n=33)$ (Fig. 2), but showed similar levels in the remaining four forest types, larch plantation (25), mature mixed forest (26), mature conifer forest (27) and secondary mixed forest (27). The species' activity density in the different forest types differed greatly, with traps in secondary broadleaved forests (1977 individuals) and mature mixed forest (2014 individuals) reflecting a significantly higher activity density of carabid beetles than the other three forest types, with mature conifer forest (1885) and secondary mixed forest (1860) forests samples showing intermediate activity densities, while larch plantations harbored the assemblages with the lowest recorded activity densities ( $\mathrm{n}=1337$ specimens). The most dominant species in our samples belonged to the genus Pterostichus, with Pt. silvestris, Pt. interruptus and Pt. adstrictus contributing $18.1 \%, 16.9 \%$ and $16.5 \%$ of all individuals, respectively. Pt. maryseae contributed a further $10.4 \%$ and Pt. bituberculatus $9.9 \%$. When comparing between forest types, there was a clear differentiation with regard to dominant species. Pt. maryseae and Pt. adstrictus dominated in the larch forest, where these two species accounted for $38 \%$ and $21.2 \%$ of all sampled individuals, respectively. Pt. silvestris dominated in the mature mixed forest (25.4\%), while Pt. silvestris and Pt. interruptus dominated in both the mature conifer forest (25.5\% and $21.9 \%$, respectively) and the secondary mixed forest ( $20 \%$ and $25.1 \%$, respectively).

In terms of the estimated species richness, Chao 1 estimates show that the larch plantation forest potentially contains a large number of species that we missed in our samples, leading to an overall highest estimated species richness of all forest types (Fig. 2). Nonetheless, the large confidence intervals indicate that with the exception of secondary broadleaved versus mature mixed forests, the estimated species richness was not significantly different between the forest types, despite a general trend for the mature forests to harbor a lower estimated species richness than secondary forests and the forest plantation plots. 
The standardized extrapolated species richness $(n=4000$ individuals $)$ for each forest type substantiates this pattern, with the five confidence bands not intersecting for species richness $(\mathrm{q}=0)$ if coverage exceeds $50 \%$, species richness in the secondary broadleaved forest and in the secondary mixed forest were significantly higher than in other forest types for standardized sample covers between 50\% and 93\% (Fig. 3, left panel). Nonetheless, only the species richness in mature conifer forest and larch plantations showed statistically significant differences. In terms of diversity indices that reflect, to increasing degree, the evenness as additional diversity component to species richness ( $\mathrm{q}=1$-Shannon diversity and $\mathrm{q}=2$-Simpson's diversity), results indicate that larch plantation forests harbor a less diverse assemblage than the other forest types, with secondary broadleaved forests showing the highest levels of diversity (Fig. 3, central and right panel). The differentiation between larch plantations and the remaining forest plots increased with increasing Hill number, indicating that plantation assemblages are strongly dominated by a small set of species.

\section{Seasonality and spatial turnover patterns in beetle assemblages}

In terms of the community composition of carabid assemblages, distinct changes occur both according to habitat types and during the sampling seasons. When emphasizing dominant species (CNESS $m=1$, Fig. 4), assemblages in the two mature forest types and in the secondary mixed forests show great similarities in their composition at each sampling event, assemblages in larch plantations are dominated by a distinctly different set of dominant species, while the dominant species in the assemblages of secondary broadleaved forest are in an intermediate position between the plantation forests and the mature forest/mixed secondary forest assemblages at all times. Trends for the similarity in overall assemblage patterns (CNESS $m=10$, Fig. 4) showed a similar trend.

241 patterns in carabid assemblages for both $m=1$ and $m=10$ (Fig. 4), species assemblages representing

242 the two mature forest types and the mixed secondary forest assemblages showed strong similarities 243 in their species composition throughout the four sampling times, resulting in four distinctive 244 temporal clusters for these plots with the exception of the mature conifer forest, where the beetle 
community appears to remain fairly stable in late summer. The dominant species in the plantation forest assemblages in contrast remained almost constant between early June and July (CNESS $m=$ 1, Fig. 4), with plantation forest assemblages always strongly differentiated from the mature and mixed secondary forest plots at all times and for both sample sizes. The secondary broadleaved forest assemblages occupied intermediate positions between the plantation forests and the other three forest types throughout the summer months, while again showing a very distinct seasonal variation.

Relative influence of forest type and seasonality on the composition of carabid assemblages

The occurrence of the 15 common carabid species that individually accounted for more than $0.7 \%$ of the overall number of individuals in this study area was strongly influenced by both habitat types and seasonality (Fig. 5A). Seasonality-linked factors could be linked to $49.9 \%$ of the observed variation, while $37.1 \%$ could be associated with forest type - specific factors. The 22 rare species that individually accounted for less than $0.7 \%$ of the number of individuals in our study were predominantly related to changes in seasonality (42.3\% explained variance) (Fig. 5B). These species showed much less clear preferences for different forest types (5.6\% explained variance).

\section{Discussion}

\section{Species diversity and differentiation between different forest types}

Based on our results, we can clearly reject the original hypothesis that mature forests harbor a higher carabid diversity than the other forest types. Our observations of species diversity peaking instead in the naturally regenerating, overall relatively tree species-poor, secondary broadleaved forest strongly dominated by birch (B. platyphylla) and poplar (P. davidiana) trees that represent two early-mid succession species (Zhou et al., 2013) came as a big surprise, not least since this outcome is also inconsistent with previous studies from China's regenerating forests. Zou et al. (2015) for example reported a high alpha diversity in mature forest plots when compared to plots representing secondary forests, and Magura et al. (2003) and Yu et al. (2006) similarly report the 
species richness and abundance of carabid assemblages to be higher in old-growth forests when compared to young, regenerating forests. Blanchet et al. (Blanchet et al., 2013) also suggest that highly productive forests that are rich in tree species support more diverse ground beetle assemblages. The lowest diversity of carabids in larch plantations in contrast confirms a trend widely reported in the literature: that mono-dominant plantation forest types commonly harbor a lower carabids diversity than natural secondary and mature forests. This trend was for example also seen at forests on Dongling Mountain (Warren-Thomas et al., 2014) and Changbai Mountain (Zou et al., 2015). It also aligns with a number of studies outside China that report a reduced diversity of ground beetles in plantation forests compared to natural forests (Butterfield \& Benitez, 1992; Butterfield et al., 1995; Fahy \& Gormally, 1998; Jukes et al., 2001; Jung et al., 2014; Oxbrough et al., 2016). Nonetheless, a number of studies have provided more nuanced results in this context, with for example Yu et al.'s $(2006 ; 2008)$ investigations of species diversity in plantations showing significant decreases in species diversity and abundance directly after reforestation of logged broadleaved forests with larch plantations, while they eventually recorded more species and individuals in young conifer plantations than in older, naturally regenerated forests. A number of further studies have found greater or equal insect species abundance and richness in plantations in comparison to mature forests (Koivula et al., 2002; Lawton et al., 1998; Niemelä, 1993; Oxbrough et al., 2012; Ramos, 2000). A wide range of factors have been proposed to explain this phenomenon, such as an overriding influence of climatic conditions, for example associated with altitudinal change, on the species distributions and hence diversity of insects(Axmacher et al., 2004; Zhang et al., 2009; Zou et al., 2015), or a strong link of forest insect diversity to specific heterogeneity in microhabitats and microclimatic conditions of different forest types(Axmacher et al., 2004; 2009; Warren-Thomas et al., 2014; Yu et al., 2008), with particular importance for carabids of the humidity in the litter layer (Koivula et al., 1999; Magura et al., 2005) and the degree of canopy cover (Fuller et al., 2008).

Although it conforms to numerous other studies, the low diversity of carabids in the larch plantations in our study area is nonetheless somewhat surprising, given that this forest has been protected for 50 years and is characterized by dense herbaceous undergrowth. Furthermore, the altitude, and depth of the humus layer of the plantation forest plots was similar to both, the secondary 
mixed forest and the mature mixed forest. Nonetheless, the undergrowth of the larch forests was more strongly dominated by grasses when compared to the herb-dominated vegetation in the other forest types, and the high vegetation density by these plants at ground level might impede the movement and hence also the hunting efficiency of ground beetles. It could also have a negative impact on the effectiveness of the pitfall traps. The results from both the rarefaction/extrapolation and species richness estimation that are specifically designed to account for such differences do furthermore raise the question if the recorded low diversity in the larch plantations is genuine or relates to a low sample completeness, and only a significant further sampling initiative could fully clarify the situation. What is nonetheless becoming very clear is that larch plantations vary greatly in the actual species assemblage present in these forests when compared to the other forest types.

This difference could not only relate to the aforementioned different structure of the undergrowth vegetation, but also to differences in the herbivorous prey species composition associated with grass-dominated undergrowth that might preferentially benefit a specific set of predatory carabid species. Related to this, the predatory carabid larvae might also be affected by a different soil macrofauna that results from the different nature of the needle litter produced by larch trees in comparison to other litter types, with $\mathrm{Wu}$ et al. (2006) reporting a distinctly lower abundance and richness of soil animals under larch plantations than under mature forests. We also observed that the canopy coverage of mature and secondary forests was higher than that in the larch plantations, which could also help to explain the differences in carabid communities between plantation forests and the other forest types. Yu et al. (2008) suggested that a high canopy cover as encountered particularly in the mature forests and the mixed secondary forest might be a prerequisite for the occurrence of forest specialists, and the similarity in assemblages in the latter forest types can be seen as supporting this hypothesis.

The diversity peak of carabids in secondary, birch (B. platyphylla) and poplar (P. davidiana)dominated broadleaved forests could be related to micro-diversification in this habitat and its distinctiveness in habitat conditions when compared to the other studied forest types. The growth of birch and poplar during about 50 years can be seen as representing an advanced development of an early succession stage in the regional forest community, with these species likely to gradually 
become replaced by hardwood species. This contrasts greatly to the structure of the mixed secondary forest, where it is likely that saplings survived the logging about five decades ago or tree species quickly regenerated from the seed-bank, hence triggering a regrowth of a tree species assemblage that showed strong similarities to the mature forests, in effect eliminating the early successional stages characterized by birch and poplar dominance. In terms of the intermediate disturbance hypothesis (Connell, 1978), it could overall be argued that the 50 year-old broadleaved, birch- and poplar-dominated secondary forest plots represent an intermediate stage of succession. The resulting forest might hence allow for the persistence of a diverse carabid assemblage (Schirmel et al., 2012; Skłodowski, 2016) comprising of generalist species, of carabids adapted to early, open successional stages, as well as of species more commonly associated with late successional stages once tree mature forest plots further supports this theory. Additionally, the secondary broadleaved forest was generally encountered in areas of high ground water table or near the local river, with the resulting damp soil conditions potentially benefitting a subset of hygrophilous specialists or mesophilous species within the regional species pool, with Worthen and Merriman (2013) reporting that many carabid species prefer moist or mesic environments.

\section{Species turnover patterns and composition influenced by seasonality versus forest type}

While there was a very strong seasonality signal observable for each forest type, mature forests and secondary mixed forests followed very similar turnover in their species assemblages, a result contradicting our third hypothesis and indicating that these forests share a very similar species pool throughout the seasons. We assume that this assemblage represents a local set of forest specialist species that originally occurred in the native forest communities. The similarity of mature and secondary mixed forest assemblages hence indicates the potential great value of secondary forests that resemble mature forests in their tree species composition for the conservation and strengthening of assemblages of forest specialist invertebrates, since they appear to provide similar habitat conditions to both the mature conifer and mature mixed forests with not only similar tree species, but also similar shrub and undergrowth vegetation(Yu et al., 2008) and similar variations in canopy 
density.

The pronounced seasonality in all carabid species assemblages, irrespective of forest type, can be related to a number of know environmental determinants that influence the spatio-temporal occurrence patterns of these beetles. At the beginning of June and the end of August, our study area experiences great differences in key climatic factors like temperature and precipitation that also greatly impact soil humidity. The increased temperatures and amounts of precipitation in our study area in July and August could provide optimal positions for both, thermophilic and hygrophilous carabid species, while xerophilous and mesic species will find more suitable conditions earlier in summer, with the distinct climatic shifts in the weather patterns of our study area in our view explaining the significant change in the community structure over the study period.

As pine plantation forests in Britain (Jukes et al., 2001), in New Zealand (Brockerhoff et al., 2005) and in northern China (Zou et al., 2015) have previously been identified as potential habitats of rare carabid species, plantation forests in the Zhangguangcai Mountains appear to support at least distinct sets of carabid species, while the overall rarity of the respective species in the wider region remains unknown. Species only encountered in the larch plantation and secondary broadleaved forests include Pterostichus maryseae, Sun \& Shi (Sun et al., 2018), a newly described species that is only known from these forests.

With regards to the pronounced and habitat-specific seasonality patterns observed in our study area, previous studies have shown that asynchronous seasonal cycles and patterns can attribute to the reduction of interspecific competition among carabid beetles (Tauber \& Tauber 1981; Werner \& Raffa, 2003). Lundgren et al. (2009) similarly hypothesized that seasonal niche partitioning might contribute to the maintenance of a diverse and abundant epigeal predator community.

Seasonal variations are associated with distinct changes in temperature and precipitation, two key factors influencing general activity, flight and foraging behavior of carabid species (Saska et al., 2010; Kotze et al., 2011). Locally rare species that responded chiefly to seasonal patterns, but appeared less sensitive to habitat types, might have more specific temperature and precipitationrelated niche spaces, while the general importance of seasonality in both, rare and common carabid 
species, shows how strongly the assemblage overall potentially responds to climatic changes in their ambient environment.

\section{Conclusion}

Overall, our study indicates that plantation forests and broadleaved secondary forests, with their distinct canopy tree species composition compared to mature forests, harbor ground beetle assemblages that are distinctly different to mature forest assemblages. In contrast, mixed secondary forests with a very similar canopy tree species composition to mature forests, despite their much younger age, were inhabited by remarkably similar assemblages in our study area. Our results furthermore indicate a very distinct seasonal signal in all carabid assemblages across the summer months, explaining large parts of the variation in assemblage compositions observed in our study.

In terms of the conservation of forest specialist species, our results suggest that forest plantations should be planted with a set of local species that also dominate potential mature forest plots in the respective area, and that secondary forests consisting predominantly of early pioneer species like birch or poplar could greatly benefit from additional planting of later successional species. Overall, we believe that the current approach of planting large-scale monocultures of often non-local species is detrimental to forest biodiversity, in turn also hampering ecosystem services like biological pest control that are associated with highly species-rich assemblages that contain a large proportion of specialist species. The most effective way to improve the future expansion of China's forest area would be to allow nature to take its course, while potentially speeding up successional processes by targeted, sparse planting of local, late-successional tree species in areas where secondary forests are dominated strongly by early successional trees.

\section{Acknowledgments}

We thank Zhang Ying for the logistic assistance and Bai Qifu for their guidance in this study area. We are very grateful to Professor Shi Hongliang from the Beijing Forestry University for their help with the carabid identification and to Professor Shi Fuchen from Nankai University for their help with the plant identification. This study was supported by the National Natural Science 
Foundation of China (31770567) and the Ministry of Science and Technology (2017YFC0506402).

\section{References}

Axmacher, J.C., Brehm, G., Hemp, A., Tünte, H., Lyaruu, H.V., Müller-Hohenstein, K. \& Fiedler, K. (2009) Determinants of diversity in afrotropical herbivorous insects (Lepidoptera: Geometridae): plant diversity, vegetation structure or abiotic factors? Journal of Biogeography, 36, 337-349.

Axmacher, J.C., Holtmann, G., Scheuermann, L., Brehm, G., Müller-Hohenstein, K. \& Fiedler, K. (2004) Diversity of geometrid moths (Lepidoptera: Geometridae) along an Afrotropical elevational rainforest transect. Diversity and Distributions, 10, 293-302.

Blanchet, F.G., Bergeron, J., Spence, J.R. \& He, F. (2013) Landscape effects of disturbance, habitat heterogeneity and spatial autocorrelation for a ground beetle (Carabidae) assemblage in mature boreal forest. Ecography, 36, 636-647.

Borcard, D., Gillet, F. \& Legendre, P. (2011) Numerical Ecology with R. Use R! series Springer Science, New York.

Brandmayr, P., Zetto, T. \& Roberto, P. (2005) I Coleotteri Carabidi per la valutazione ambientale e la conservazione della biodiversità Manuale operativo APAT, Roma Italy.

Brockerhoff, E.G., Lisa A. B. \& Hervé J. (2005) Role of exotic pine forests in the conservation of the critically endangered New Zealand ground beetle Holcaspis brevicula (Coleoptera: Carabidae). New Zealand Journal of Ecology, 29, 37 - 43.

Butterfield, J. \& Benitez, M.J. (1992) Effect of mixed-species tree planting on the distribution of soil invertebrates. Special Publications of the British Ecological Society, 255-265.

Butterfield, J., Luff, M.L., Baines, M. \& Eyre, M.D. (1995) Carabid beetle communities as indicators of conservation potential in upland forests. Forest Ecology and Management, 79, 63-77.

Carabidae of the World (2018) Carabidae subfamilies. $<$ http://www. http://carabidae.org/taxa $>21$ December 2018.

Cardoso P., Silva I., De Oliveira N.G. \& Serrano A.R.M.(2007) Seasonality of spiders (Araneae) in Mediterranean ecosystems and its implications in the optimum sampling period. Ecological Entomology, 32, 516-526.

Chao, A. (1984) Nonparametric estimation of the number of classes in a population. Scandinavian Journal of Statistics, 265-270. 
Chao, A., Gotelli, N.J., Hsieh, T.C., Sander, E.L., Ma, K.H., Colwell, R.K. \& Ellison, A.M. (2014) Rarefaction and extrapolation with Hill numbers: a framework for sampling and estimation in species diversity studies. Ecological Monographs, 45-67.

Chao, A., \& Lou J. (2012) Coverage - based rarefaction and extrapolation: standardizing samples by completeness rather than size. Ecology, 93, 2533-2547.

Chen, X., Ju, Q. \& Lin, K. (2014) Development Status, Issues and Countermeasures of China's Plantation. World Forestry Research, 27, 54-59.

Connell, J.H. (1978) Diversity in tropical rain forests and coral reefs. Science, 199, 1302-1310.

Devries, P.J., Walla, T.R. \& Greeney, H.F. (1999) Species diversity in spatial and temporal dimensions of fruit-feeding butterflies from two Ecuadorian rainforests. Biological Journal of the Linnean Society, 68, 333-353.

Digweed, S.C., Currie, C.R., Carcamo, H.A. \& Spence, J.R. (1995) Digging out the "digging-in effect" of pitfall traps: Influences of depletion and disturbance on catches of ground beetles (Coleoptera : Carabidae). Pedobiologia, 39, 561-576.

Dornelas M., Magurran A.E., Buckland S.T., Chao A., Chazdon R.L., Colwell R.K., Curtis T., Gaston K.J., Gotelli N.J., Kosnik M.A., McGill B., McCune J.L., Morlon H., Mumby P.J., Ovreas L., Studeny A. \& Vellend M. (2013) Quantifying temporal change in biodiversity: challenges and opportunities. Proceedings of the Royal Society, 280, 20121931.

Fahy, O. \& Gormally, M. (1998) A comparison of plant and carabid beetle communities in an Irish oak woodland with a nearby conifer plantation and clearfelled site. Forest Ecology and Management, 110, $263-273$.

FAO (2001) State of the World's Forests 2001. Food and Agriculture Organization of the United Nations, Rome, $1-175$.

FAO (2015a) Global Forest Resources Assessment 2015. Desk reference Food and Agriculture Organization of the United Nations, Rome, 1-241.

FAO (2015b) Global Forest Resources Assessment 2015: How are the world's forests changing? Second edition Food and Agriculture Organization of the United Nations, Rome, 1-44.

FAO (2016) State of the World's Forests 2016. Forests and agriculture: land-use challenges and opportunities. Food and Agriculture Organization of the United Nations, Rome, 1-107.

Fuller, R.J., Oliver, T.H. \& Leather, S.R. (2008) Forest management effects on carabid beetle communities in coniferous and broadleaved forests: implications for conservation. Insect 
Gao, G.C. \& Fu, B.Q. (2009) Advances of researches on carabid beetles as bioindicators. Chinese Bulletin of Entomology, 46, 216-222.

Gnetti, V., Bombi, P., Taglianti, A.V., Bologna, M.A., D'Andrea, E., Cammarano, M., Bascietto, M., Cinti, B.D. \& Matteucci, G. (2015) Temporal dynamic of a ground beetle community of eastern Alps (Coleoptera Carabidae). Bulletin of Insectology, 68, 299-309.

Hsieh, T.C., Ma, K.H. \& Chao, A. (2016) iNEXT: an R package for rarefaction and extrapolation of species diversity (Hill numbers). Methods in Ecology and Evolution, 7, 1451-1456.

Hua, F., Wang, X., Zheng, X., Fisher, B., Wang, L., Zhu, J., Tang, Y., Yu, D.W. \& Wilcove, D.S. (2016)

Jung, J.K., Kim, S.T., Lee, S.Y., Park, C.G., Park, J.K. \& Lee, J.H. (2014) A comparison of diversity and

Jukes, M.R., Peace, A.J. \& Ferris, R. (2001) Carabid beetle communities associated with coniferous plantations in Britain: the influence of site, ground vegetation and stand structure. Forest Ecology and Management, 148, 271-286. species composition of ground beetles (Coleoptera: Carabidae) between conifer plantations and regenerating forests in Korea. Ecological Research, 29, 877-887.

Koivula, M., Kukkonen, J. \& Niemelä, J. (2002) Boreal carabid-beetle (Coleoptera, Carabidae) assemblages along the clear-cut originated succession gradient. Biodiversity \& Conservation, 11, $1269-1288$.

Koivula, M., Punttila, P., Haila, Y. \& Niemelä, J. (1999) Leaf Litter and the Small-Scale Distribution of Carabid Beetles (Coleoptera, Carabidae) in the Boreal Forest. Ecography, 22, 424-435.

Kotze, D.J., Brandmayr, P., Casale, A., Dauffyrichard, E., Dekoninck, W., Koivula, M.J., Lövei, G.L., Mossakowski, D., Noordijk, J. \& Paarmann, W. (2011) Forty years of carabid beetle research in Europe-from taxonomy, biology, ecology and population studies to bioindication, habitat assessment and conservation. Zookeys, 100, 55-148.

Correspondence Analysis. R package version 1.0.0.(https://github.com/laijiangshan/rdacca.hp) 
Lawton, J.H., Bignell, D.E., Bolton, B., Bloemers, G.F., Eggleton, P., Hammond, P.M., Hodda, M., Holt, R.D., Larsen, T.B. \& Mawdsley, N.A. (1998) Biodiversity inventories, indicator taxa and effects of habitat modificationin tropical forest. Nature, 391, 72-76.

Legendre, P. \& Gallagher, E.D. (2001) Ecologically meaningful transformations for ordination of species data. Oecologia, 129, 271-280.

Lemenih, M., Gidyelew, T. \& Teketay, D. (2004) Effects of canopy cover and understory environment of tree plantations on richness, density and size of colonizing woody species in southern Ethiopia. Forest Ecology and Management, 194, 1-10.

Loreau, M., \& Nolf, C.L. (1993) Occupation of space by the carabid beetle Abax ater. Acta Oecologica, 14: $247-258$.

Lövei, G.L. \& Sunderland, K.D. (1996) Ecology and behavior of ground beetles (Coleoptera: Carabidae). Annual Review of Entomology, 41, 231-256.

Lundgren J.G., Nichols S., Prischmann D.A. \& Ellsbury M.M. (2009) Seasonal and diel activity patterns of generalist predators associated with Diabrotica virgifera immatures (Coleoptera: Chrysomelidae). Biocontrol Science and Technology, 19, 327 - 333.

Magura, T., Tóthmérész, B. \& Elek, Z. (2003) Diversity and composition of carabids during a forestry cycle. Biodiversity \& Conservation, 12, 73-85.

Magura, T., Tóthmérész, B. \& Elek, Z. (2005) Impacts of Leaf-litter Addition on Carabids in a Conifer Plantation. Biodiversity \& Conservation, 14, 475-491.

Meng, Q. (2006) Discussionon Effects of Plantation on Biodiversity Conservation. World Forestry Research, 19, 1-6.

Morales-Hidalgo, D., Oswalt, S.N. \& Somanathan, E. (2015) Status and trends in global primary forest, protected areas, and areas designated for conservation of biodiversity from the Global Forest Resources Assessment 2015. Forest Ecology and Management, 352, 68-77.

Niemelä, J. (1993) Mystery of the missing species: species-abundance distribution of boreal groundbeetles. Annales Zoologici Fennici, 30, 169-172.

Oksanen, J., Guillaume, F.B., Friendly, M., Kindt. R., Legendre. P., McGlinn. D., Minchin, P.R., O'Hara, R.B., Simpson, G.L., Solymos. P., Stevens, M.H.H., Szoecs, E. \& Wagner, H. (2019) Vegan: Community ecology package. R package version 2.5-6. R Foundation for Statistical Computing, Vienna, Austria. https://cran.r-project.org/web/packages/vegan/

Oxbrough, A., French, V., Irwin, S., Kelly, T.C., Smiddy, P. \& O’Halloran, J. (2012) Can mixed species 

18.

Oxbrough, A., Garcíatejero, S., Spence, J. \& O'Halloran, J. (2016) Can mixed stands of native and non-

Potapov, P., Yaroshenko, A., Turubanova, S., Dubinin, M., Laestadius, L., Thies, C., Aksenov, D., Egorov, A., Yesipova, Y., Glushkov, I., Karpachevskiy, M., Kostikova, A., Manisha, A., Tsybikova, E. \&

Ramos, F.A. (2000) Nymphalid butterfly communities in an amazonian forest fragment. Journal of Research on the Lepidoptera, 35, 29-41.

R Core Team. (2019) R: A language and environment for statistical computing. Version 3.6.1. Vienna, Austria: R Foundation for Statistical Computing.

Saska P., Martinkova Z. \& Honek A. (2010) Temperature and rate of seed consumption by ground beetles (Carabidae). Biological Control, 52, 91 - 95.

Schirmel, J., Blindow, I. \& Buchholz, S. (2012) Life-history trait and functional diversity patterns of ground beetles and spiders along a coastal heathland successional gradient. Basic and Applied Ecology, 13, 606-614.

Silva-Rodríguez, E.A., Ortega-Solís, G.R. \& Jiménez, J.E. (2010) Conservation and ecological implications of the use of space by chilla foxes and free-ranging dogs in a human-dominated landscape in southern Chile. Austral Ecology, 35, 765-777.

Shutt, J.D., Burgess M.D. \& Phillimore A.B. (2019) A spatial perspective on the phenological distribution of the spring woodland caterpillar peak. The American Naturalist, 194, E109-E121.

Skłodowski, J. (2016) Ground beetle assemblages across a habitat gradient in a stream watershed during 16 years of observation. Bulletin of Entomological Research, 106, 827-839.

Sun, X.J., Shi, H.L., Sang, W.G. \& Axmacher, J.C. (2018). Two new species of Feroperis Lafer (Carabidae, Pterostichus) from China, with a key to all known Chinese species in this subgenus. ZooKeys, 799, 95-114.

Tauber C.A. \& Tauber M.J. (1981) Insect seasonal cycles: genetics and evolution. Annual Review of Ecology and Systematics, 12, $281-308$. 
Wang, G., Innes, J.L., Lei, J., Dai, S. \& Wu, S.W. (2007) China's forestry reforms. 1556-1557.

Wang, X., Müller, J., An, L., Ji, L., Liu, Y., Wang, X. \& Hao, Z. (2014) Intra-annual variations in abundance and species composition of carabid beetles in a temperate forest in Northeast China. Journal of insect conservation, 18, 85-98.

Warren-Thomas, E., Zou, Y., Dong, L., Yao, X., Yang, M., Zhang, X., Qin, Y., Liu, Y., Sang, W. \& Axmacher, J.C. (2014) Ground beetle assemblages in Beijing's new mountain forests. Forest Ecology and Management, 334, 369-376.

Watson, J.E., Evans, T., Venter, O., Williams, B., Tulloch, A., Stewart, C., Thompson, I., Ray, J.C., Murray, K. \& Salazar, A. (2018) The exceptional value of intact forest ecosystems. Nature Ecology \& Evolution, 2, 599-610.

Werner, S.M. \& Raffa, K.F. (2003) Seasonal activity of adult, ground-occurring beetles (Coleoptera) in forests of northeastern Wisconsin and the Upper Peninsula of Michigan. The American midland naturalist, 149, 121 - 133.

Wickham, H., Hester, J. \& Chang, W. (2019) devtools: Tools to Make Developing R Packages Easier. Retrieved from: https://CRAN.R-project.org/package=devtools (R package version 2.2.1).

Worthen, W.B. \& Merriman, D.C.G. (2013) Relationships between Carabid Beetle Communities and Forest Stand Parameters: Taxon Congruence or Habitat Association? Southeastern Naturalist, 12, $379-386$.

Wu, D., Zhang, B. \& Chen, P. (2006) Ecological distributions and community compositions of the soil insect larvae in the habitats of different land-use types in Changchun city. Ecology and Environment, 15, 802-806.

Yu, X.D., Zhou, H.Z. \& Luo, T.H. (2002) Distribution Patterns and Their Seasonal Changes of Carabus Beetles in Dongling Mountain Region Near Beijing. Acta Ecologica Sinica, 22, 1724-1733.

Yu, X.D., Luo, T.H. \& Zhou, H.Z. (2006) Distribution of carabid beetles among regenerating and natural forest types in Southwestern China. Forest Ecology and Management, 231, 169-177.

Yu, X.D., Luo, T.H. \& Zhou, H.Z. (2008) Distribution of carabid beetles among 40-year-old regenerating plantations and 100-year-old naturally regenerated forests in Southwestern China. Forest Ecology and Management, 255, 2617-2625.

Zhang, X.P., Wang, M.B. \& Liang, X.M. (2009) Quantitative classification and carbon density of the forest vegetation in Lüliang Mountains of China. Plant Ecology, 201, 1-9. 
Zhou, J.P., Ning, Y.C. \& Zheng, X.X. (2013) Study on spatial structure of poplar-birch secondary forest in Jingouling Forest Farm. Journal of Central South University of Forestry \& Technology, 33, 74-78.

Zou, Y., Sang, W.G., Bai, F., Brennan, E., Diekman, M., Liu, Y.H., Li, L.T., Marples, A., Shi, H.L., Sui, Z.Z., Sun, X.J., Wang, C.L., Wang, X., Warren - Thomas, E., Yang, X., Yu, Z.R. \& Axmacher, J.C (2019a). Large-scale $\alpha$-diversity patterns in plants and ground beetles (Coleoptera: Carabidae) indicate a high biodiversity conservation value of China's restored temperate forest landscapes. Diversity and Distributions, 25: 1613 - 1624 .

Zou, Y. \& Axmacher, J.C. (2019b) The Chord-Normalized Expected Species Shared (CNESS)-distance represents a superior measure of species turnover patterns. Methods in Ecology and Evolution, 00, $1-8$.

Zou, Y., Sang, W., Wang, S., Warren-Thomas, E., Liu, Y., Yu, Z., Wang, C. \& Axmacher, J.C. (2015) Diversity patterns of ground beetles and understory vegetation in mature, secondary, and plantation forest regions of temperate northern China. Ecology and Evolution, 5, 531-42.

\section{Legend}

Fig.1. Map showing the location of our study region and a detailed map showing the location of the 20 study plots representing the five forest types. LP: Larch plantation, SBF: Secondary broadleaved forest, SMF: Secondary mixed forest, MMF: Mature mixed forest and MCF: Mature conifer forest

Fig.2. Carabid species richness, estimated richness and abundance in five forest types (Error bars represent standard error of species estimated richness; LP: Larch plantation, SBF: Secondary broadleaved forest, SMF: Secondary mixed forest, MMF: Mature mixed forest and MCF: Mature conifer forest)

Fig.3. Coverage-based rarefaction (solid line segment) and extrapolation (dotted line segments) sampling curves with 95\% confidence intervals (shaded areas) for the carabids data of five forest types (LP: Larch plantation, SBF: Secondary broadleaved forest, SMF: Secondary mixed forest, MMF: Mature mixed forest and MCF: Mature conifer forest), separately by diversity order: $\mathrm{q}=0$ (species richness, left panel), q = 1 (Shannon's entropy index, middle panel) and q=2 (the inverse of Simpson's concentration index, right panel). The five different icons represent the reference samples, the numbers in parentheses are the sample coverage and the observed Hill numbers for each reference sample 
Fig.4. Non-metric multi-dimensional scaling of carabid samples based on the CNESS dissimilarity matrix for a minimum sample size $(\mathrm{m}=1$, Stress $=0.12)$ and the maximum common sample size $(\mathrm{m}$ $=10$, Stress $=0.07 ;$ LP: Larch plantation, SBF: Secondary broadleaved forest, SMF: Secondary mixed forest, MMF: Mature mixed forest and MCF: Mature conifer forest

Fig.5. Hierarchical partitioning for canonical correspondence analysis and redundancy analysis plots showing the relationship between carabid species compositions, seasonality and forest type; (A)

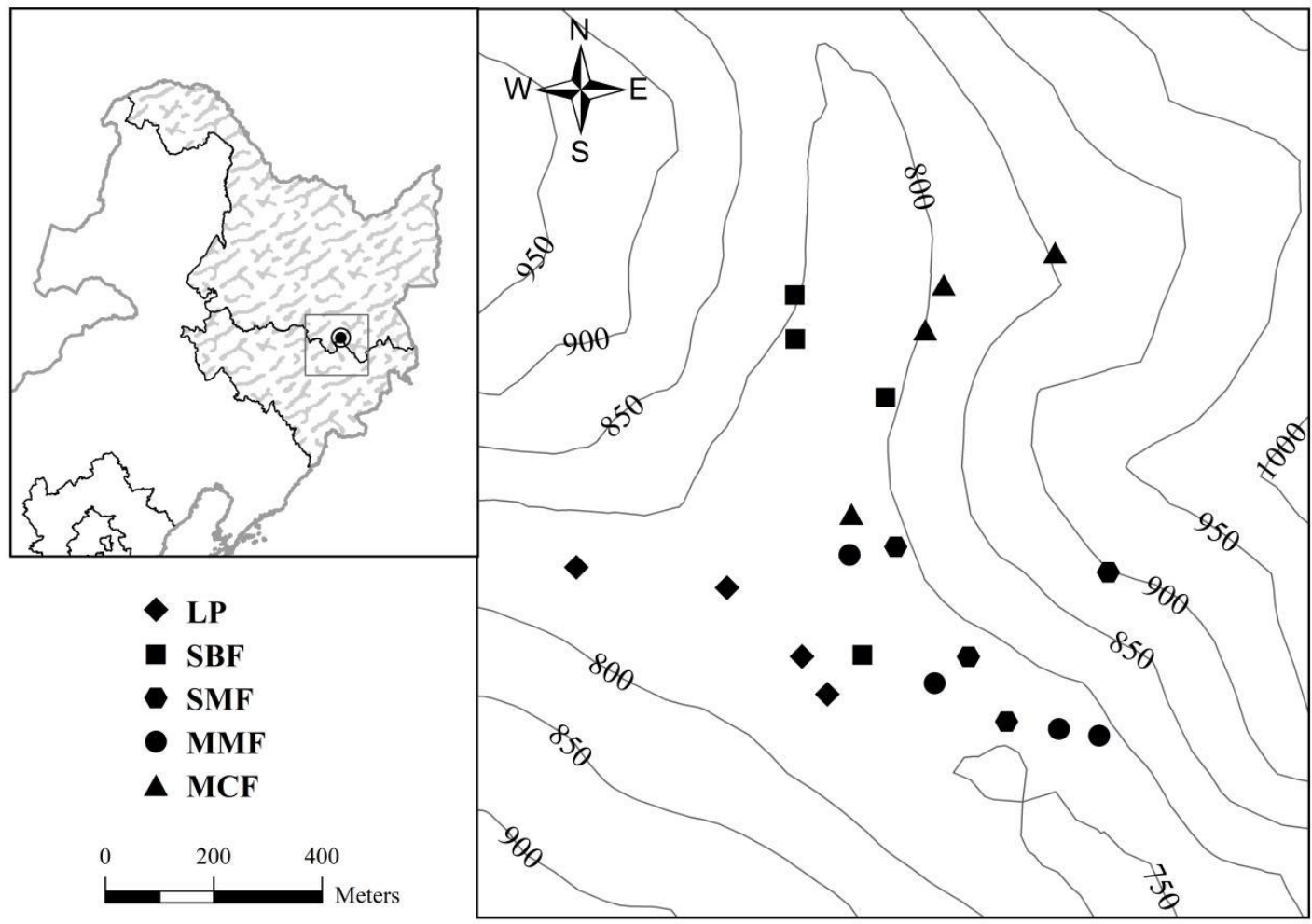




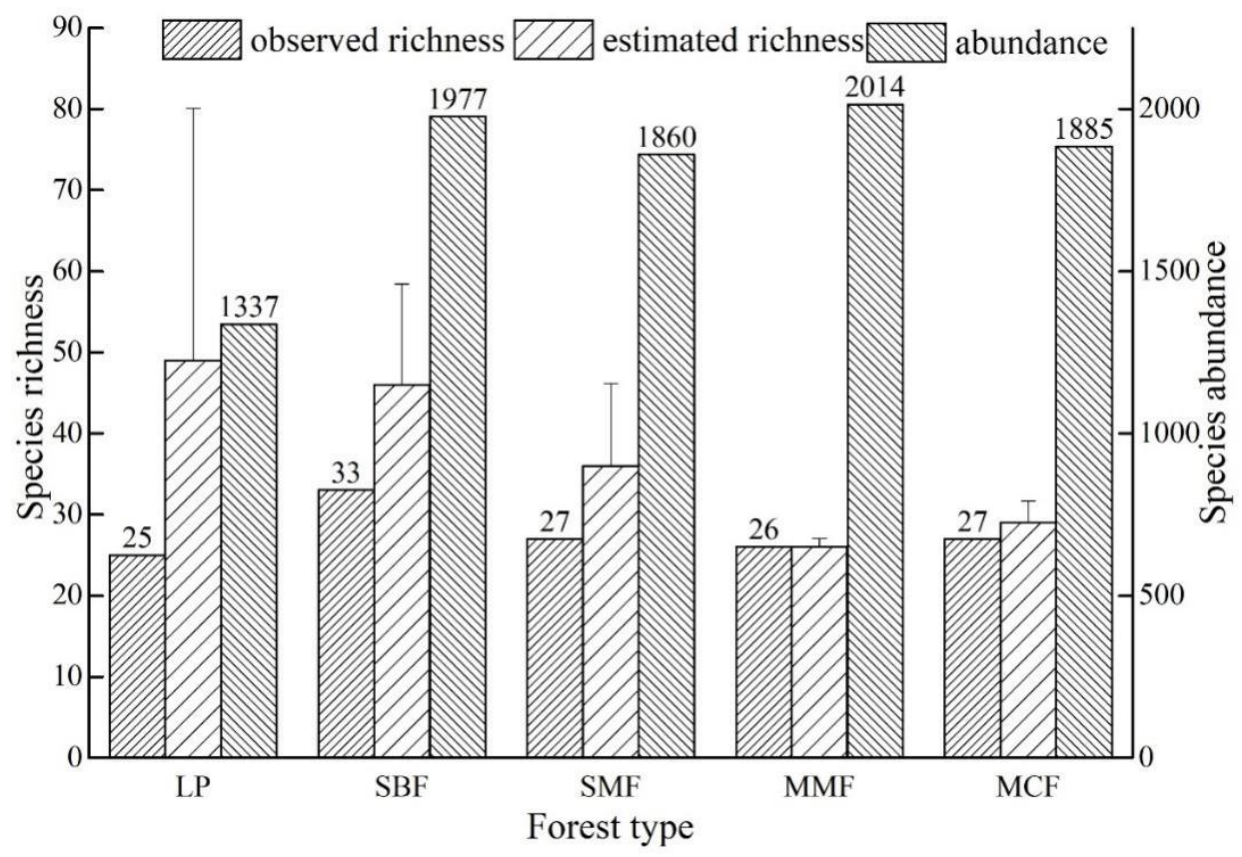

640

Fig. 3
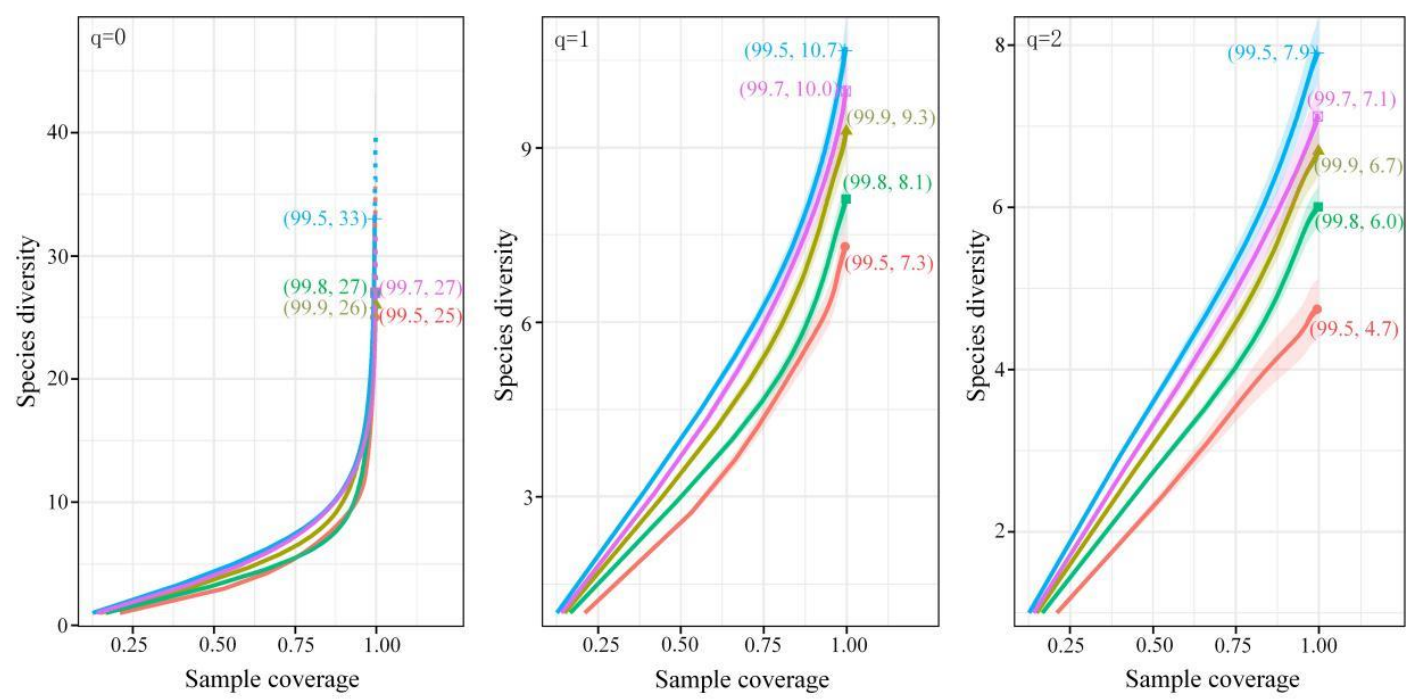

641

LP $\boxplus \mathrm{SBF}$ SMF $\triangle \mathrm{MMF} \square \mathrm{MCF}-$ interpolated $\cdots$ extrapolated

642 

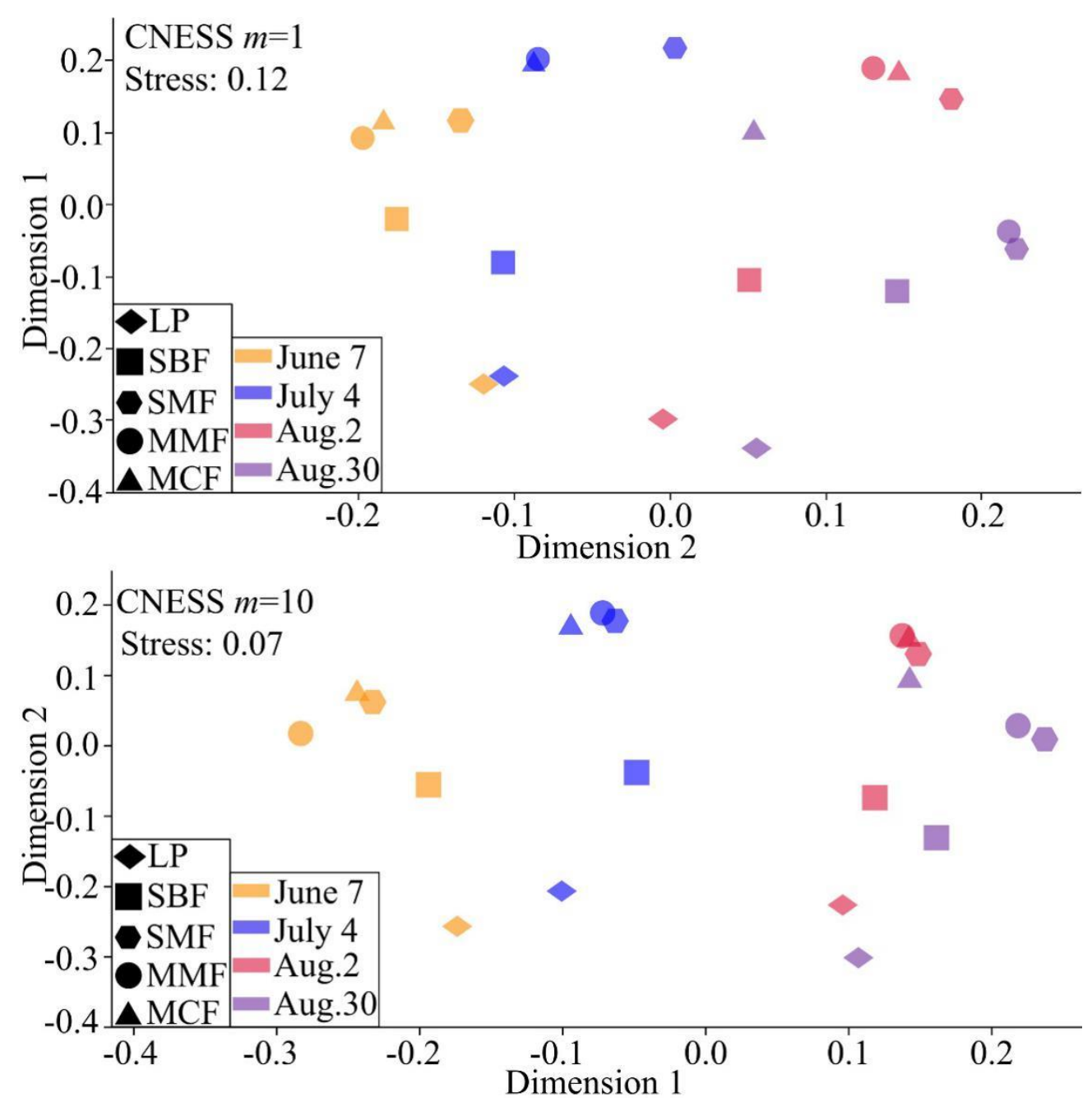

Fig. 5

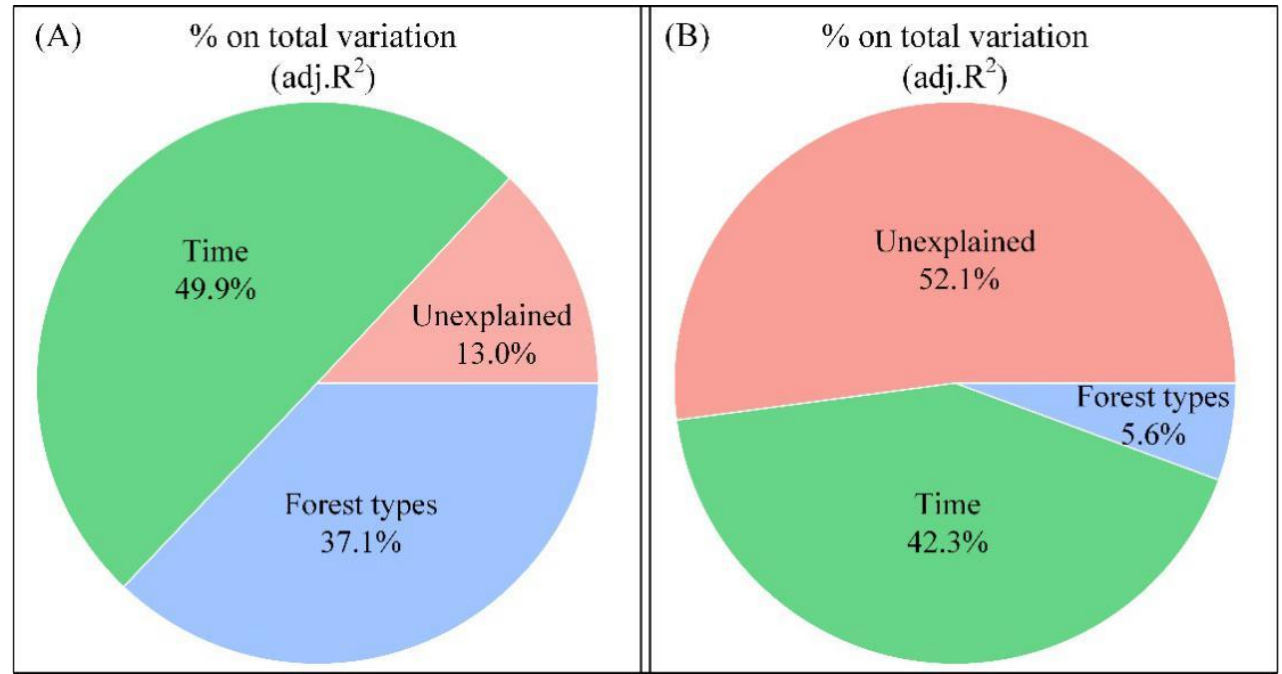

